\title{
Are There Differences in Life-Satisfaction, Optimism, Pessimism and Perceived Stress between Therapeutic and Mastery Exercisers? A Preliminary Investigation
}

\author{
Attila Szabo, Szilvia Boros, Júlia Patakiné Bősze \\ Institute of Health Promotion and Sport Sciences, ELTE Eötvös Loránd University, Budapest, Hungary
}

\begin{abstract}
Background. Most incentives for exercise can be grouped into health-related 'therapeutic' and challenge or enjoyment-related 'mastery' categories. If these incentives are not independent of personal needs and expectations, their associated psychological profiles may vary.

Methods. Based on the broaden-and-build theory, we examined the hypothesis that mastery exercise is associated with more favourable psychological profile, as reflected in greater life-satisfaction, optimism, pessimism, and perceived stress, than therapeutic exercise or no-exercise (the control group).

Results. The results indicated that people who exercised for a mastery purpose $(n=57)$ reported greater optimism, lower pessimism and lower perceived stress than non-exercisers $(n=57)$ but they only scored higher in optimism in contrast to the therapeutic exercisers $(n=129)$ who did not differ from the controls in any of the measures. A composite score of a psychological profile, obtained by subtracting the sum of negative ratings from the sum of positive ratings, revealed that mastery exercisers exhibited higher scores than non-exercisers who did not differ from therapeutic exercisers.

Conclusion. These preliminary findings suggest that two very general motives for exercise might be associated with different psychological profiles, which deserves future research attention in the better understanding of the psychological effects of exercise.
\end{abstract}

Keywords: life-satisfaction, optimism, non-exerciser, perceived stress, pessimism.

\section{INTRODUCTION}

$\mathrm{P}$ eople voluntarily engage in leisurely physical exercise for a primary reason, although secondary motives for participation may often prevail (Allison et al., 2005). Having continuous access to abundant information about the health benefits of exercise, perhaps the most often cited reason for exercise can be related to health (Brown, Miller, \& Adams, 2017; Cash, Now, \& Grant, 1994; Mathes \& Battista, 1985). However, novelty, selfchallenge, pure enjoyment, and fun can also be primary motivators in leisure sports and exercise (Kilpatrick, Hebert, \& Bartholomew, 2005; Wienke $\&$ Jekauc, 2016). The principal reasons for exercise can be grouped into two general categories, one being linked to health and the other being linked to anything else than health, with mastery (selfchallenge, skill-learning, development, control over life-experiences) being perhaps the closest collective term for a second category. Indeed, Robbins and Joseph (1985), relatively long ago, have introduced to concepts of 'therapeutic' and 'mastery' exercise.

Therapeutic exercise can be a positively- or negatively-reinforced behaviour (Szabo, 1995). In the prevention stage, when the person is healthy, exercise is more likely maintained by positive 
reinforcement surfacing as a gain in health. However, when the health is at risk, in accord to the health belief model (Rosenstock, 1974), exercise could become a means to avoid the potential health hazard. These motivations can be extrinsic or intrinsic. For example, there is a consensus that exercise reduces both state anxiety (Ensari, Greenlee, Motl, \& Petruzzello, 2015) and depression (Daley, 2008) which could motivate exercise behaviour in the affected individuals via negative reinforcement to avoid getting worse or to prevent relapse, as well as via positive reinforcement to gain better feeling state and to improved health. Such behaviour seems to be intrinsically motivated, but consideration of others (family, partner) and work capacity, status maintenance (survival needs) could be the primary reasons for engaging in the behaviour, in which case it is rather externally motivated. According to Robbins and Joseph (1985), runners who experienced the therapeutic benefits of running have learned to rely on it when the need arises, hence a situation-driven switch between the two forms of motivation and reinforcement may occur. In case of extreme stress and/or trauma, the social image-conscious exerciser uses exercise as a means of coping/escape (Egorov \& Szabo, 2013), because it is perceived to be a socially accepted form of positive addiction (Glasser, 1976) in contrast to drug or alcohol use for the same reason, which are behaviours linked to a negative social stigma.

Mastery exercise is a source of self-fulfilment, self-challenge, sense of accomplishment and novelty (Robbins \& Joseph, 1985). Popular magazines and books cite personal accounts of exercisers achieving often superhuman goals resulting in self-fulfilment. It does not exclude the social pleasure of exercise, if the exercise is performed in team or group setting, but the here and now experience is the ultimate reward stemming from positive reinforcement (Allen-Collinson \& Leledaki, 2014). This feeling often culminates in flow, which is thought to be the optimal human experience (Csikszentmihalyi, 2017). While therapeutic exercisers may also experience flow, the health-related expectation associated with exercise outcome remains the principal driving force behind their exercise behaviour, or else they no longer would be therapeutic exercisers. Outcome expectations have significant effects on exercise behaviour (Mothes et al., 2016; Resnick, Palmer, Jenkins, \& Spellbring, 2000; Resnick \& Spellbring, 2000). Early research revealed that outcome expectations were better predictors of exercise behaviour than self-efficacy (Jette et al., 1998). In fact, the reason for selfselected exercise can hardly be separated from outcome expectancies.

Assigning exercise a therapeutic or a mastery role (Robbins \& Joseph, 1985), could reflect the anticipation of the exercise effect. Early research revealed that sport participation is linked to enjoyment and/or mastery while exercise or fitness class participation was more closely associated with body-related or health incentives (Frederick \& Ryan, 1993). Later Kilpatrick et al. (2005) showed that college students who engaged in competitive sports primarily cited mastery reasons for their participation, while those who engaged in exercise most often cited health reasons. These authors suggested that sport participation might be intrinsically motivated whereas exercise participation could be externally motivated. However, leisure exercises are also performed for non-health reasons fuelled by intrinsic motivation (Allen-Collinson \& Leledaki, 2014; Clough, Shepherd, \& Maughan, 1989; Robbins \& Joseph, 1985). Despite such information, to the best of these authors' knowledge, the prevalence and concomitants of therapeutic and mastery exercise in leisure exercisers were not studied to date. Thus, possible differences between these groups concerning a more positive or negative psychological profile, is not available, but there are correlational data suggesting that a more positive psychological profiles may be linked to mastery orientation (Frederick \& Ryan, 1993), which agrees with the broaden-and-build theory (Fredrickson, 2001) positing that intrinsic positive experiences generate positive emotions.

A positive psychological profile can be interpreted in terms of the subjective well-being of the individual which could be approached from hedonic and eudaimonic perspectives (Ryan \& Deci, 2001). Hedonic well-being is closely associated with pleasure and it is strongly related to life-satisfaction (Diener, 1984). Fulfilment and growth (i.e., mastery) are more closely associated with eudaimonic well-being (Fromm, 1981) and are linked to positive psychological functioning as well as well-being (McMahan \& Renken, 2011). Perceived stress is inversely related to lifesatisfaction (Alleyne, Alleyne, \& Greenidge, 2010; Malinauskas, 2010; Yew, Lim, Haw, \& Gan, 2015). Similarly, there is evidence that optimism is positively, whereas pessimism is negatively related 
to life-satisfaction (Chang, 1997; Yew et al., 2015). From these variables, therefore, it is possible to generate a psychological profile reflected by a set of specific psychological indices related to one's well-being which allows comparison between therapeutic and mastery exercisers.

The aim of this preliminary cross-sectional investigation was twofold. First, we were interested in appraising the percentage of leisure exercisers citing therapeutic and mastery reasons as primary incentives for their exercise behaviour. According to Kilpatrick et al. (2005), we would expect that most of these exercisers would cite a health-related reason. Second, based on the contention that leisure exercisers exercise for mastery reasons too, we expected to find a lower number of respondents who would fit into this category. Based on this conjecture, we also planned to compare a limited psychological profile by measuring life-satisfaction, optimism, pessimism, and perceived stress, of therapeutic and mastery exercisers. Relying on Robbins and Joseph (1985) and the broaden-and-build theory, we hypothesized that mastery exercisers would exhibit a healthier or more positive psychological profile than therapeutic exercisers and non-exercisers.

\section{METHODS}

Participants. Participants were recruited via a call for participation posted on general social media. The call for participants informed potential respondents that the study examines the link between lifestyle and psychological indices. To avoid priming while also securing a control group, exercising was not a criterion for participation. Consequently, non-exercisers were also eligible to participate if they were aged 18 years or above, but answers from athletes were eliminated, because the study was aimed at examining leisure exercisers. To increase the sample size, the snowball method (Goodman, 1961) was also employed. The study was conducted with ethical approval obtained from the Research Ethics Committee of the Faculty of Education and Psychology at ELTE Eötvös Loránd University in Budapest, Hungary. Additionally, the study conformed to the ethical guidelines for research with human participants of the Helsinki Declaration (World Medical Association, 2008). The research also followed the British Psychological Society's guidelines for Internet-mediated research (British Psychological Society, 2017).
Sample size was determined a priori with the G* Power v. 3.1 software (Faul, Erdfelder, Buchner, $\&$ Lang, 2009). Based on a medium effect size, six groups ( 3 exercise status $x 2$ gender) three predictors (exercise status, age, gender), $\alpha=.05,1-\beta=.95$ ), and four dependent measures, the estimated sample size was $142 .{ }^{1}$ In one-month 327 responses were collected online. After eliminating the incomplete answers and those from sport/competitive athletes, 243 responses were fully acceptable. They came from 98 men and 145 women. The participants' mean $(M)$ age was 31.54 years, standard deviation $(S D)=12.38$, range 18-71 years. Fifty-seven respondents reported that they do not exercise, 125 participated in individual exercises, and 61 in group exercises. Half of the exercisers $(n=93)$ participated in organized exercise while the other half $(n=93)$ in self-planned exercise. Most exercisers $(n=129)$ reported a health-related reason for exercising while close to one third (57) reported a challengerelated motive for their usual exercise. Most nonexercisers reported lack of time $(n=26)$ followed by laziness $(n=13)$ and other unique reasons $(n=$ 18 ) as excuses for not exercising.

Materials. In the first section, the survey contained the demographic questions (i.e., gender, age, exercise habits). The remaining sections comprised three questionnaires assessing life-satisfaction, optimism, pessimism, and perceived stress.

Satisfaction with Life. The Satisfaction with Life Scale (SWLS; Diener, Emmons, Larsen, \& Griffin, 1985) was adopted to measure general life-satisfaction. The original SWLS has 5 items, which are rated on a 7-point Likert scale ranging from strongly disagree to strongly agree. A sample item from the SWLS is: 'In most ways my life is close to my ideal'. The internal reliability of the scale is good (Cronbach $\alpha=.79-.89$ ). In the present study we used the psychometrically validated Hungarian version of this scale, the SWLS-HU (Martos, Sallay, Désfalvi, Szabó, \& Ittzés, 2014). The reported internal reliability of the SWLS-HU is .84. In the current study the internal reliability of the SWLS-HU was .88 .

Optimism and pessimism. The revised Life Orientation Test (LOT-R) was used to assess optimism and pessimism (Scheier, Carver, \& Bridges, 1994). This scale contains 10 items.

\footnotetext{
1 As a control for power, after completing the data analyses the new Pillai's trace value was used for calculating the effect size. The posteriori determined sample size was 219 , which was still lower than the actual sample size (243).
} 
Three items assess optimism, three items assess pessimism, and the remining four are only filler items. A sample item for optimism is: 'In uncertain times, I usually expect the best' and a sample item for pessimism is: 'If something can go wrong for $m e$, it will'. Respondents are asked to indicate the extent to which they agree or disagree with the items on a 5-point Likert scale ranging from strongly agree to strongly disagree. Originally, the LOT-R was constructed to measure optimism as a unidimensional construct, with optimism and pessimism being bipolar opposites (Scheier \& Carver, 1985). However, later it was demonstrated that optimism and pessimism of the LOT-R reflect independent constructs (Herzberg, Glaesmer, \& Hoyer, 2006). Psychometric properties of the twodimensional LOT-R are good (Herzberg et al., 2006). Its internal reliability was reported to be .71 for optimism and .68 for pessimism (Herzberg et al., 2006). In the current work we used the psychometrically validated Hungarian scale, the LOT-HU (Bérdi \& Köteles, 2010). Its reported internal reliability ranges between .77 to .81 . In the current study these values were .75 for optimism and .69 for pessimism, respectively.

Perceived Stress Scale (PSS; Cohen, Kamarck, \& Mermelstein, 1983). The PSS is a widely used psychological instrument for assessing the perception of stress. It consists of 14 items with each item rated on a 5-point Likert type scale ranging from 1 (never) to 5 (very often). A sample item from the PSS is: 'In the last month, how often have you been upset because of something that happened unexpectedly?' The PSS measures the degree to which situations in one's life over the past month are evaluated as stressful. The tool's reported internal reliability ranged between $\alpha=.84$ to .86 (Cohen et al., 1983). In the present study we used the 14-item validated Hungarian version of this scale, the PSS-HU (Stauder \& Konkoly Thege, 2006). Its originally reported internal reliability is .88 . This value was slightly higher in the current study (.90).

Procedure. The participants completed the questionnaires anonymously on the Qualtrics online research platform (Qualtrics, 2017; Snow, 2013). To access the survey, participants had to give consent to their participation by selecting an 'I agree' button. As mentioned earlier, only the fully completed $(100 \%)$ responses were included in the present study. Data were downloaded in a
Statistical Package for Social Sciences (SPPS v. 25) file and analysed with the same statistical software.

Grouping. Exercisers were grouped into a 'therapeutic' and a' mastery' subgroups by careful analyses of the responses they provided as their reason for their exercise. Any reason associated with physical (fitness, firmness, looks, weight, etc.) or psychological (dealing with stress, improving mood, self-esteem, etc.) was coded as therapeutic. Motives associated with challenge (running faster, lifting greater weight, doing better, trying out new things, exploring self-limits, etc.) were coded as mastery reasons. Two of the experimenters fully agreed on the final classifications. The nonexercisers formed the third group.

Data analysis. Given that age (Trujillo, Brougham, \& Walsh, 2004) and gender (Butt, Weinberg, Breckon, \& Claytor, 2011) differences in the motives for exercise were reported in the literature, to examine the hypotheses that positive (life-satisfaction and optimism) and negative (perceived stress and pessimism) psychological constructs differ between the two exercise- and no-exercise groups, a Multivariate Analysis of Covariance (MANCOVA), using age and gender as covariates, was employed. Subsequently, based on the positive and negative dependent measures a 'psychological profile' was calculated by adding the ratings on life-satisfaction and optimism from which the sum of the ratings of perceived stress and pessimism was subtracted. A univariate analysis of covariance (ANCOVA), including age and gender as covariates, was performed to examine the group differences in this composite index.

\section{RESULTS}

Close to one-third $(30.6 \%)$ of the eligible respondents could be classified as mastery exercisers while the rest were therapeutic exercisers providing a health reason for their exercise. The results of the MANCOVA yielded a statistically significant multivariate main effect for the exercise groups (Pillai's Trace $=.077, F_{8,468}=2.33$, $p=.018$, effect size: partial Eta squared $\left[p \eta^{2}\right]=$ $.038,1-\beta=.886)$. Both gender and age emerged to be statistically significant covariates (Pillai's Trace $=.094, F_{4,233}=6.06, p<.001, p \eta^{2}=.094$, $1-\beta=.985$, and Pillai's Trace $=.143, F_{4,233}=9.73$, $p<.001, p \eta^{2}=.143,1-\beta=1.00$, respectively). The univariate tests demonstrated that after controlling for gender and age, statistically significant 
$(p<.05)$ group differences emerged in three out of four dependent measures (optimism, pessimism, and perceived stress) while it only approached statistical significance for life-satisfaction $(p=.075)$. The summary of the univariate tests is presented in Table 1. Post-hoc Bonferroni tests showed that there were no differences in life-satisfaction between the three groups, but those in the mastery exercise group exhibited statistically significantly higher optimism than those exercising for a therapeutic reason and the non-exercising controls (refer to the Table). Further, mastery exercisers reported lower pessimism and less perceived stress in contrast to non-exercisers but did not differ from therapeutic exercisers.

After controlling for gender and age, the ANCOVA on the composite index of the psychological profile yielded a statistically significant effect for groups $\left(F_{2,239}=5.34, p=.005\right.$, $\left.p \eta^{2}=.043,1-\beta=.836\right)$. Bonferroni corrected posthoc tests revealed that only the mastery exercise group differed from non-exercisers $(p=.004)$, but not from the therapeutic exercisers. The latter group did not differ in this composite psychological score from the non-exerciser control group (Figure).
Table. Group differences in four psychological measures

Note. Descriptive statistics (means $[\mathrm{M}]$ and standard deviation $[\mathrm{SD}]$ ) for four dependent measures in the therapeutic exercise $(n=129)$, mastery exercise $(n=57)$, and no-exercise control $(n=57)$ groups, also showing the $F$ values $(d f=2,236)$ of the univariate tests, their significance levels $(p)$ and the effect sizes (partial Eta squared $\left[p \eta^{2}\right]$. Superscripts indicate statistically significant differences between the groups, after controlling for gender and age, as based on Bonferronicorrected post-hoc tests: (Optimism ${ }^{\mathrm{a}-\mathrm{b}} p=$ $.022,{ }^{\mathrm{b}-\mathrm{c}} p<.001 ;$ Pessimism ${ }^{\mathrm{b}-\mathrm{c}}, p=.034$ Perceived stress $\left.{ }^{\mathrm{b}-\mathrm{c}} p=.016\right)$.

\begin{tabular}{|c|c|c|c|c|c|}
\hline $\begin{array}{c}\text { Dependent } \\
\text { Measures }\end{array}$ & Group & $M(S D)$ & $F$ & $p$ & $p \eta^{2}$ \\
\hline Life-satisfaction & $\begin{array}{l}\text { Therapeutic } \\
\text { Mastery } \\
\text { Control }\end{array}$ & $\begin{array}{l}25.25(6.02) \\
26.30(5.72) \\
23.65(7.26)\end{array}$ & 2.62 & .075 & .022 \\
\hline Optimism & $\begin{array}{l}\text { Therapeutic } \\
\text { Mastery } \\
\text { Control }\end{array}$ & $\begin{array}{l}11.26(2.63)^{\mathrm{a}} \\
12.30(2.34)^{\mathrm{b}} \\
10.65(2.49)^{\mathrm{c}}\end{array}$ & 9.02 & .001 & .071 \\
\hline Pessimism & $\begin{array}{l}\text { Therapeutic } \\
\text { Mastery } \\
\text { Control }\end{array}$ & $\begin{array}{l}6.97(2.56) \\
6.46(2.54)^{b} \\
7.75(3.28)^{c}\end{array}$ & 3.29 & .039 & .027 \\
\hline Perceived stress & $\begin{array}{l}\text { Therapeutic } \\
\text { Mastery } \\
\text { Control }\end{array}$ & $\begin{array}{l}37.21(7.41) \\
35.44(8.95)^{b} \\
38.79(8.52)^{\mathrm{c}}\end{array}$ & 3.97 & .020 & .033 \\
\hline
\end{tabular}

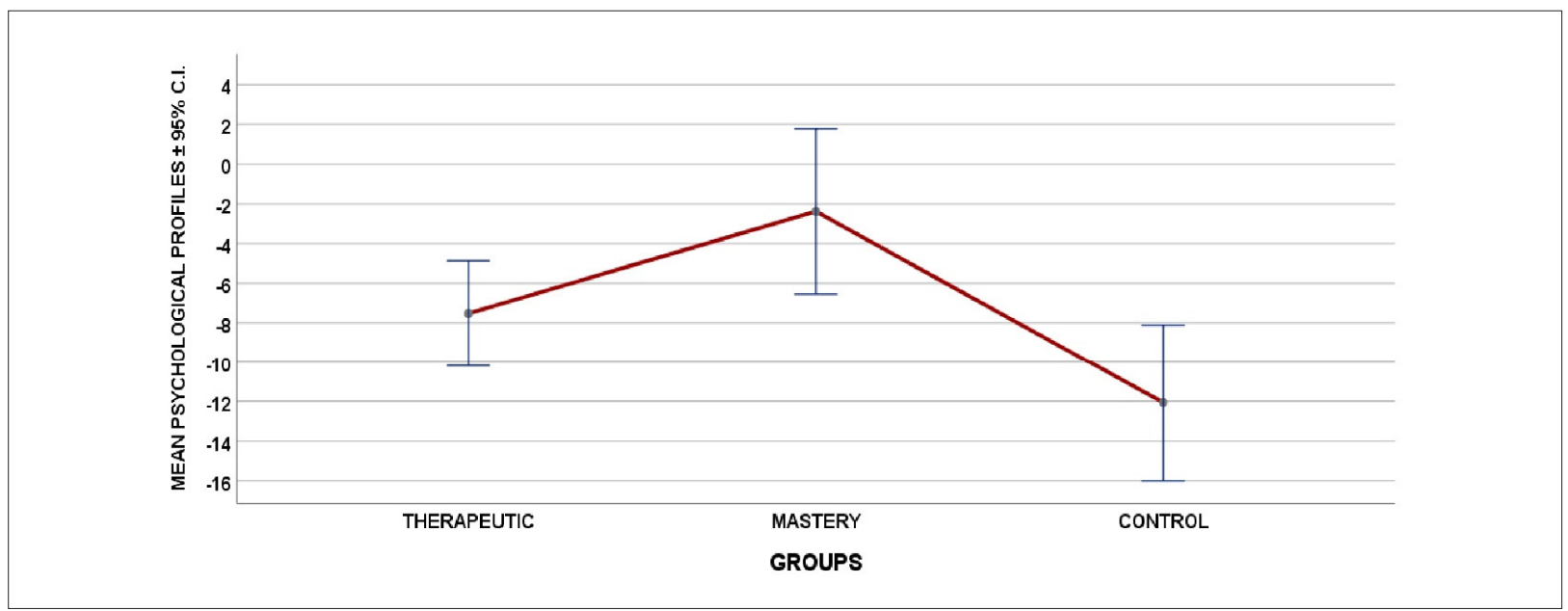

Figure. Composite score of psychological profile

Note. This profile reflects the difference between positive and negative measures showing that the most favourable profile was exhibited by mastery exercisers, but their score only differed from non-exercising controls' score which did not differ from therapeutic exercisers' score. The values are negative because of the maximum value of the negative item was greater (85) than the maximum of the positive items (50). 


\section{DISCUSSION}

The main findings in the current study are: 1) A significant proportion of the leisure exercisers are motivated by mastery reasons, but about twice as many commit themselves to exercise for a therapeutic reason; 2) Despite a general tendency of mastery exercisers showing a more positive psychological profile to therapeutic exercisers, the two only differed from each other in optimism with former group scoring higher than the latter; 3) Mastery exercisers differed in three out of four measures from non-exercisers and exhibited an overall superior psychological profile in contrast to this group; 4) Therapeutic exercisers did not differ from non-exercisers in any of the four dependent measures.

The prevalence of leisure exercisers who exercised for a mastery reason was about one third in the current sample. This figure is relatively close to that obtained by Kilpatrick et al. (2005) in whose study 30/105 exercisers could be clearly identified as mastery exercisers (based on Table 3, p. 92, Kilpatrick et al. 2005). These results merely confirm that leisure exercise is often performed for mastery reasons, but the therapeutic reasons for exercise appear to be twice as many. These figures should be interpreted as approximations since neither the current study or Kilpatrick et al.'s (2005) study examined a representative sample. To obtain a realistic estimate of the prevalence of mastery and therapeutic exercisers population-wide studies are necessary.

The mean values obtained on the four dependent measures were higher for the positive items (life-satisfaction and optimism) and lower for the negative items (perceived stress and pessimism) in the mastery- versus the therapeutic-exercise group. However, only optimism was statistically significantly higher in the mastery compared to therapeutic group (refer to Table 1). Despite earlier research showing that optimism is related to the belief that exercise contributes to health in leisure exercisers (Rabinowitz, Melamed, Weisberg, Tal, \& Ribak, 1992), in this study mastery exercisers scored higher than those citing a health-related reason for their exercise. One explanation is that mastery reasons for exercise participation are comparable to reasons for sport participation (challenge, exploiting limits, competitiveness, etc.). Past research revealed that athletes are more optimistic than non-athletes (Venne, Laguna, Walk, \& Ravizza, 2006). Mastery exercise reasons may largely overlap with athletic incentives, which in turn may explain the here revealed differences in optimism between mastery and therapeutic exercisers. Another possible explanation could be that therapeutic exercise, in general, may be more externally motivated in contrast to mastery exercise which is more internally motivated (Kilpatrick et al., 2005) and since intrinsic motivation is positively related to optimism (Shin \& Kelly, 2013) this relationship could account for the differences in optimism between the two groups. However, since motivation was not assessed in in this work, this explanation remains a hypothesis for future research in the area.

While there were no differences in lifesatisfaction, the mastery exercisers differed in the other three dependent measures from the nonexercisers. These findings agree with the results of an earlier work showing that exercising individuals reported lower occupational stress than their nonexercising counterparts (Taylor, 2000). However, in that study no mastery versus therapeutic exercise orientation was examined. In this context, it should be noted that despite not reaching the accepted level of statistical significance, therapeutic exercisers also tended to report lower levels of perceived stress than non-exercisers. ${ }^{2}$ Concerning optimism, mastery exercisers differed from nonexercisers too in this measure. This finding agrees with other reports in the literature. Indeed, a positive association between optimism and exercise behaviour was reported in several studies (Hamid 1990; Holahan \& Suzuki, 2006; Mulkana \& Hailey, 2001). However, negative findings were also reported in some studies (Boehm et al., 2018). The dissonant findings may be related to the diverse samples studied as well as to the conceptualization of exercise behaviour, not mentioning the potential mediating factors.

\footnotetext{
2 While it was not a purpose of the study, we also tested whether exercisers combined (therapeutic and mastery) differed in the dependent measures from non-exercisers and, after controlling for age and gender, apart from lifesatisfaction that only approached statistical significance $(p=.059)$ all other measures differed between the two groups $(p<05)$ in the favour of the exercisers.
} 
The finding that therapeutic exercisers did not differ from the non-exercisers in any of the four dependent measures was unexpected, because there are several reports disclosing a superior psychological profile in exercisers compared to non-exercisers. For example, differences were reported in body-image and psychological wellbeing (Goodwin, Astbury, \& McMeeken, 2000), in mood profiles (Wilson, Morley, \& Bird, 1980), in job satisfaction, occupational stress, and selfefficacy (Taylor, 2000), in resilience to stress (Childs \& de Wit, 2014), and perceived bodily appearance (Loland, 2000). No reports are available in relation to the variables examined in the current work. However, these results, also confirmed via the results obtained with the composite score of psychological profile (see Figure 1), suggest that if such difference is to be reported in the future, it can be primarily attributed to mastery rather than therapeutic exercise. Therefore, exercising for health reasons does not appear to yield more favourable psychological indices than not exercising at all. This finding raises the need for further work to elucidate the connection between motivational features associated with both therapeutic and mastery exercises (extrinsic, intrinsic, introjected, identified, positively- or negatively-reinforced) and psychological indices.

Strengths and limitations. The strengths of the current preliminary work are: 1) It shows that examining the mental benefits of exercise from therapeutic and mastery perspectives appears to be feasible; 2) It reveals that the primary reasons for exercise are possibly associated with different levels of psychological indices; and 3) It raises the question whether therapeutic exercise has any psychological benefits in contrast to no exercise at all. The limitations of the study, as identified by the authors, are: 1) Tested self-selected volunteers; 2) Lacks motivation data; 3) The posteriori grouping resulted in large sample size differences between therapeutic exercisers and the other two groups.

\section{CONCLUSIONS}

The results of the study agree with the broadenand-build theory, in that mastery exercises characterized by anticipation of positive events (challenge, growth, excitement, etc.) is associated with superior psychological profile in contrast to no-exercise, but only with greater optimism in contrast to therapeutic exercise. A psychological profile derived from the difference between the sum of negative measures and the sum of positive measures confirms these findings and suggests that while the mastery exercisers do not differ from therapeutic exercisers, they exhibit a superior profile to non-exercisers. Unexpected was the finding that therapeutic exercisers did not differ in psychological profile from non-exercisers. These findings call for further systematic scrutiny of therapeutic and mastery reasons in exercise for better understanding of the relationship between the primary motive for one's exercise behaviour and the related psychological outcomes in terms of psychological indices.

Conflict of interest. The authors have no conflict of interest to declare.

Acknowledgement. Erzsébet Vig is appreciated for her assistance in setting up the online research platform.

\section{REFERENCES}

Allen-Collinson, J., \& Leledaki, A. (2014). Sensing the outdoors: A visual and haptic phenomenology of outdoor exercise embodiment. Leisure Studies, 34(4), 457-470. doi: 10.1080/02614367.2014.923499

Alleyne, M., Alleyne, P., \& Greenidge, D. (2010). Life-satisfaction and perceived stress among university students in Barbados. Journal of Psychology in Africa, 20(2), 291-297. doi: 10.1080/14330237.2010.10820378

Allison, K. R., Dwyer, J. J., Goldenberg, E., Fein, A., Yoshida, K. K., \& Boutilier, M. (2005). Male adolescents' reasons for participating in physical activity, barriers to participation, and suggestions for increasing participation. Adolescence, 40(157), 155-170.

Bérdi, M., \& Köteles, F. (2010). The measurement of optimism: The psychometric properties of the Hungar- ian version of the Revised Life Orientation Test (LOTR). Magyar Pszichológiai Szemle (Hungarian Journal of Psychology), 65(2), 273-294. doi: 10.1556/mpszle.65.2010.2.7

Boehm, J. K., Chen, Y., Koga, H., Mathur, M. B., Vie, L. L., \& Kubzansky, L. D. (2018). Is optimism associated with healthier cardiovascular-related behavior? Circulation Research, 122(8), 1119-1134. doi: 10.1161/circresaha.117.310828

British Psychological Society. (2017). Guidelines for Internet-mediated research. Retrieved from https://www. bps.org.uk/sites/bps.org.uk/files/Policy\%20 20Files/ Ethics\%20Guidelines\%20for\%20Internet mediated\%20 Research\%20\%282017\%29.pdf

Brown, T. C., Miller, B. M., \& Adams, B. M. (2017). What's in a name? Group fitness class names and women's 
reasons for exercising. Health Marketing Quarterly, 34(2), 142-155. doi: 10.1080/07359683.2017.1309212

Butt, J., Weinberg, R. S., Breckon, J. D., \& Claytor, R. P. (2011). Adolescent physical activity participation and motivational determinants across gender, age, and race. Journal of Physical Activity and Health, 8(8), 10741083. doi: 10.1123/jpah.8.8.1074

Cash, T. F., Now, P. L., \& Grant, J. R. (1994). Why do women exercise? Factor analysis and further validation of the reasons for exercise inventory. Perceptual and Motor Skills, 78(2), 539-544. doi: 10.2466/pms.1994.78.2.539

Chang, E. (1997). Optimism and pessimism as partially independent constructs: relationship to positive and negative affectivity and psychological well-being. Personality and Individual Differences, 23(3), 433-440. doi: 10.1016/s0191-8869(97)00040-8

Childs, E., \& de Wit, H. (2014). Regular exercise is associated with emotional resilience to acute stress in healthy adults. Frontiers in Physiology, 5. doi: 10.3389/ fphys.2014.00161

Clough, P., Shepherd, J., \& Maughan, R. (1989). Motives for participation in recreational running. Journal of Leisure Research, 21(4), 297-309. doi: 10.1080/00222216.1989.11969806

Cohen, S., Kamarck, T., \& Mermelstein, R. (1983). Perceived Stress Scale. PsycTESTS Dataset. doi: 10.1037/t02889-000

Csikszentmihalyi, M. (2017). Finding flow. The Psychology of Engagement with Everyday Life. Gildan: Audio Book.

Daley, A. (2008). Exercise and depression: A review of reviews. Journal of Clinical Psychology in Medical Settings, 15(2), 140-147. doi: 10.1007/s10880-0089105-z

Diener, E. (1984). Subjective well-being. Psychological Bulletin, 95(3), 542-575. doi: 10.1037/00332909.95.3.542

Diener, E. D., Emmons, R. A., Larsen, R. J., \& Griffin, S. (1985). The satisfaction with life scale. Journal of Personality Assessment, 49(1), 71-75.

Ensari, I., Greenlee, T. A., Motl, R. W., \& Petruzzello, S. J. (2015). Meta-analysis of acute exercise effects on state anxiety: An update of randomized controlled trials over the past 25 years. Depression and Anxiety, 32(8), 624 634. doi: 10.1002/da.22370

Faul, F., Erdfelder, E., Buchner, A., \& Lang, A. G. (2009). Statistical power analyses using G*Power 3.1: Tests for correlation and regression analyses. Behavior Research Methods, 41(4), 1149-1160. doi: 10.3758/brm.41.4.1149

Frederick, C. M., \& Ryan, R. M. (1993). Differences in motivation for sport and exercise and their relations with participation and mental health. Journal of Sport Behavior, 16(3), 124-146.

Fredrickson, B. L. (2001). The role of positive emotions in positive psychology: The broaden-and-build theory of positive emotions. American Psychologist, 56(3), 218226. doi: 10.1037/0003-066x.56.3.218
Fromm, E. (1981). Primary and secondary process in waking and in altered states of consciousness. Academic Psychological Bulletin, 3, 29-45.

Glasser, W. (1976). Positive addiction. Oxford, England: Harper \& Row.

Goodman, L. A. (1961). Snowball Sampling. Annals of Mathematical Statistics, 32(1), 148-170. doi: 10.1214/ aoms/1177705148

Goodwin, A., Astbury, J., \& McMeeken, J. (2000). Body image and psychological well-being in pregnancy. A comparison of exercisers and non-exercisers. The Australian and New Zealand Journal of Obstetrics and Gynaecology, 40(4), 442-447. doi: 10.1111/j.1479828x.2000.tb01178.x

Hamid, P. N. (1990). Optimism and reporting of flu episodes. Social Behavior and Personality: An International Journal, 18(2), 225-234. doi: 10.2224/ sbp.1990.18.2.225

Herzberg, P. Y., Glaesmer, H., \& Hoyer, J. (2006). Separating optimism and pessimism: A robust psychometric analysis of the Revised Life Orientation Test (LOT-R). Psychological Assessment, 18(4), 433438. doi: 10.1037/1040-3590.18.4.433

Holahan, C. K., \& Suzuki, R. (2006). Motivational factors in health promoting behavior in later aging activities. Adaptation \& Aging, 30(1), 47-60. doi: 10.1300/j016v30n01_03

Jette, A., Lachman, M., Giorgetti, M., Assmann, S., Harris, B., ... \& Krebs, D. (1998). Effectiveness of home-based, resistance training with disabled older persons. The Gerontologist, 38, 412-422.

Kilpatrick, M., Hebert, E., \& Bartholomew, J. (2005). College students' motivation for physical activity: Differentiating men's and women's motives for sport participation and exercise. Journal of American College Health, 54(2), 87-94.

Loland, N. W. (2000). The aing body: Attitudes toward bodily appearance among physically active and inactive women and men of different ages. Journal of Aging and Physical Activity, 8(3), 197-213. doi: 10.1123/ japa.8.3.197

Malinauskas, R. (2010). The associations among social support, stress, and life-satisfaction as perceived by injured college athletes. Social Behavior and Personality: An International Journal, 38(6), 741-752. doi: 10.2224/ sbp.2010.38.6.741

Martos, T., Sallay, V., Désfalvi, J., Szabó, T., \& Ittzés, A. (2014). Psychometric characteristics of the Hungarian version of the Satisfaction with Life Scale (SWLS-H). Mentálhigiéné És Pszichoszomatika, 15(3), 289-303. doi: 10.1556/mental.15.2014.3.9

Mathes, S. A., \& Battista, R. (1985). College men's and women's motives for participation in physical activity. Perceptual and Motor Skills, 61(3), 719-726

McMahan, E. A., \& Estes, D. (2011). Hedonic versus eudaimonic conceptions of well-being: Evidence of differential associations with self-reported well-being. 
Social Indicators Research, 103(1), 93-108. doi: 10.1007/s11205-010-9698-0

Mothes, H., Leukel, C., Jo, H.-G., Seelig, H., Schmidt, S., \& Fuchs, R. (2016). Expectations affect psychological and neurophysiological benefits even after a single bout of exercise. Journal of Behavioral Medicine, 40(2), 293306. doi: 10.1007/s10865-016-9781-3

Mulkana, S. S., \& Hailey, B. J. (2001). The role of optimism in health-enhancing behavior. American Journal of Health Behavior, 25(4), 388-395. doi: 10.5993/ajhb.25.4.4

Qualtrics (2017). Survey research suite: Research core ${ }^{T M}$. Provo, Utah, USA. Retrieved October 14, 2018, from: http://www.qualtrics.com

Rabinowitz, S., Melamed, S., Weisberg, E., Tal, D., \& Ribak, J. (1992). Personal determinants of leisure-time exercise activities. Perceptual and Motor Skills, 75(3), 779-784. doi: 10.2466/pms.1992.75.3.779

Resnick, B., Palmer, M. H., Jenkins, L. S., \& Spellbring, A. M. (2000). Path analysis of efficacy expectations and exercise behaviour in older adults. Journal of Advanced Nursing, 31(6), 1309-1315. doi: 10.1046/j.1365-2648.2000.01463.x

Resnick, B., \& Spellbring, A. M. (2000). Understanding what motivates older adults to exercise. Journal of Gerontological Nursing, 26(3), 34-42. doi: 10.3928/0098-9134-20000301-08

Robbins, J. M., \& Joseph, P. (1985). Experiencing exercise withdrawal: Possible consequences of therapeutic and mastery running. Journal of Sport Psychology, 7(1), 2339. doi: 10.1123/jsp.7.1.23

Rosenstock, I. M. (1974). The health belief model and preventive health behavior. Health Education Monographs, 2(4), 354-386. doi: 10.1177/109019817400200405

Ryan, R. M., \& Deci, E. L. (2001). On happiness and human potentials: a review of research on hedonic and eudaimonic well-being. Annual Review of Psychology, 52(1), 141-166. doi: 10.1146/annurev.psych.52.1.141.

Scheier, M. F., Carver, C. S., \& Bridges, M. W. (1994). Distinguishing optimism from neuroticism (and trait anxiety, self-mastery, and self-esteem): A re-evaluation of the Life Orientation Test. Journal of Personality and Social Psychology, 67(6), 1063-1078. doi: 10.1037/0022-3514.67.6.1063
Scheier, M. F., \& Carver, C. S. (1985). Optimism, coping, and health: Assessment and implications of generalized outcome expectancies. Health Psychology, 4(3), 219247. doi: 10.1037/0278-6133.4.3.219

Shin, Y. J., \& Kelly, K. R. (2013). Cross-cultural comparison of the effects of optimism, intrinsic motivation, and family relations on vocational identity. The Career Development Quarterly, 61(2), 141-160. doi: 10.1002/j.2161-0045.2013.00043.x

Snow, J. (2013). How to use Qualtrics: Handbook for research professionals. Provo, UT: Qualtrics Labs, Inc.'

Stauder, A., \& Konkoly Thege, B. (2006). Az Észlelt Stressz Kérdőív (PSS) Magyar Verziójának Jellemzői (Charactersitics of the Hungarian Version of Perceived Stress Scale). Mentálhigiéné És Pszichoszomatika, 7(3), 203-216. doi: 10.1556/mental.7.2006.3.4

Taylor, H. (2000). The difference between exercisers and non-exercisers on work-related variables. International Journal of Stress Management, 7(4), 307-309. http:// dx.doi.org/10.1023/A:1009546114515

Trujillo, K. M., Brougham, R. R., \& Walsh, D. A. (2004). Age differences in reasons for exercising. Current Psychology, 22(4), 348-367. doi: 10.1007/s12144-0041040-z

Venne, S. A., Laguna, P., Walk, S., \& Ravizza, K. (2006). Optimism levels among collegiate athletes and non-athletes. International Journal of Sport and Exercise Psychology, 4(2), 182-195. doi:10.1080/1612 197x.2006.9671792

Wienke, B., \& Jekauc, D. (2016). A qualitative analysis of emotional facilitators in exercise. Frontiers in Psychology, 7, 1-13, doi: 10.3389/fpsyg.2016.01296

Wilson, V. E., Morley, N. C., \& Bird, E. I. (1980). Mood profiles of marathon runners, joggers and non-exercisers. Perceptual and Motor Skills, 50(1), 117-118. doi: 10.2466/pms. 1980.50.1.117

World Medical Association. (2008). World Medical Association Declaration of Helsinki: Ethical principles for medical research involving human subjects. Retrieved October 14, 2018, from: https://www.wma. net/wp-content/uploads/2018/07/DoH-Oct2008.pdf

Yew, S. H., Lim, K. M. J., Haw, Y. X., \& Gan, S. K. E. (2015). The association between perceived stress, life-satisfaction, optimism, and physical health in the Singapore Asian context. Asian Journal of Humanities and Social Sciences (AJHSS), 3(1), 56-66. 